\title{
Visualizing and Quantifying Fusarium oxysporum in the Plant Host
}

\author{
Andrew Diener \\ Molecular, Cell \& Developmental Biology, University of California, Los Angeles, 90095, U.S.A. \\ Submitted 17 February 2012. Accepted 7 August 2012.
}

\begin{abstract}
Host-specific forms of Fusarium oxysporum infect the roots of numerous plant species. I present a novel application of familiar methodology to visualize and quantify $F$. oxysporum in roots. Infection in the roots of Arabidopsis thaliana, tomato, and cotton was detected with colorimetric reagents that are substrates for Fusarium spp.-derived arabinofuranosidase and $N$-acetyl-glucosaminidase activities and without the need for genetic modification of either plant host or fungal pathogen. Similar patterns of blue precipitation were produced by treatment with 5-bromo-4-chloro-3indoxyl- $\alpha$-L-arabinofuranoside and 5-bromo-4-chloro-3-indoxyl-2-acetamido-2-deoxy- $\beta$-D-glucopyranoside, and these patterns were consistent with prior histological descriptions of $F$. oxysporum in roots. Infection was quantified in roots of wild-type and mutant Arabidopsis using 4-nitrophenyl- $\alpha$-L-arabinofuranoside. In keeping with an expectation that disease severity above ground is correlated with $F$. oxysporum infection below ground, elevated levels of arabinofuranosidase activity were measured in the roots of susceptible $a g b 1$ and $r f o 1$ while a reduced level was detected in the resistant eirl. In contrast, disease severity and $F$. oxysporum infection were uncoupled in tir3. The distribution of staining patterns in roots suggests that $A G B 1$ and $R F O 1$ restrict colonization of the vascular cylinder by $F$. oxysporum whereas EIRI promotes colonization of root apices.
\end{abstract}

Fusarium wilt in Arabidopsis is an experimental pathosystem for studying the genetics of host resistance to and pathogenesis of vascular wilt fungi (Diener and Ausubel 2005; Ospina-Giraldo et al. 2003). Pathogenic forms, or formae speciales, of the soilborne filamentous fungus Fusarium oxysporum are responsible for host-specific vascular diseases, commonly described as wilts (Kistler 1997). In particular, three formae speciales (namely, F. oxysporum f. sp. conglutinans, F. oxysporum f. sp. raphani, and $F$. oxysporum f. sp. mathioli) are isolated from diseased cabbage (Brassica spp.), radish (Raphanus sativus), and garden stock (Mathiola incana), respectively (Bosland and Williams 1987). Foliar wilt symptoms in these field hosts, such as stunting, epinasty, yellowing, and premature senescence in leaves, are recapitulated in the related crucifer Arabidopsis, and wild accessions of Arabidopsis exhibit a remarkable range of responses to $F$. oxysporum f. sp. conglutinans, $F$. oxysporum $\mathrm{f}$. sp. mathioli, and $F$. oxysporum $\mathrm{f}$.

Corresponding author: A. Diener; E-mail: diener@lifesci.ucla.edu

* The $e$-Xtra logo stands for "electronic extra" and indicates that one supplementary figure is published online and Figure 7 appears in color online. sp. raphani, from complete resistance to strong susceptibility (Diener and Ausubel 2005). Nevertheless, host specificity is preserved in this model host plant because Arabidopsis remains completely resistant to $F$. oxysporum formae speciales from non-crucifer hosts. At least six quantitative trait loci (QTL) contribute to the natural diversity of resistance among Arabidopsis accessions (Diener and Ausubel 2005). The gene identity of one QTL, RESISTANCE TO F. OXYSPORUM 1 (RFO1), as a putative pattern-recognition receptor suggests that quantitative resistance represents variation in innate immunity.

The appearance of more or less severe wilt disease in genetically defined Arabidopsis mutants has implicated the corresponding genes and underlying molecular processes in host response to $F$. oxysporum infection (Berrocal-Lobo and Molina 2008; Michielse and Rep 2009). Several mutants, including agbl (arabidopsis g protein beta 1), eirl (ethylene insensitive root 1 ), and tir3 (transport inhibitor resistant 3 ), in particular, affect resistance to $F$. oxysporum $\mathrm{f}$. sp. conglutinans and also have an altered basipetal transport of the plant hormone auxin (Kazan and Manners 2009; Kidd et al. 2011; Mudgil et al. 2009; Trusov et al. 2006). In agb1, loss of the sole Arabidopsis G-protein $\beta$ subunit increases basipetal transport of auxin in roots and exhibits acute wilt symptoms that appear sooner in agbl than in the wild type (Mudgil et al. 2009; Trusov et al. 2006). In contrast, mutation of an auxin efflux carrier in eirl abolishes the basipetal auxin transport coordinating gravitropic root growth and suppresses wilt symptoms (Kidd et al. 2011; Luschnig et al. 1998). Moreover, the pleiotropic tir3 mutation, which reduces basipetal auxin transport in stems, also strongly suppresses wilt disease (Kazan and Manners 2009; Ruegger et al. 1997). At first glance, AGB1, EIR1, and TIR3 would appear to be components of a basipetal auxin transport process that promotes wilt susceptibility.

Talboys and others characterize vascular wilt diseases as pathogen-host interactions with three phases (Beckman 1987; Beckman and Roberts 1995; Talboys 1972). In the primary determinative (or prevascular) phase, the pathogen penetrates the root surface, traverses tissues outside the vascular cylinder, and enters vascular elements in the root. In the secondary determinative (or vascular) phase, the pathogen then spreads through the vascular system with pervasive growth in xylem vessels. The rapidity and strength of the immune response in the first two phases determine the efficacy of the host's natural resistance. In the final, expressive phase, symptoms become evident in the aboveground foliage. In most genetic studies of Fusarium wilt disease, resistance is equated with the suppression of symptoms that occur in the expressive phase even though $F$. oxysporum infection, in the two determinative phases, is largely confined to the belowground roots (Anderson et al. 
2004; Diener and Ausubel 2005; Trusov et al. 2006). Fewer studies measure both the severity of foliar symptoms and the extent of fungal colonization, and these two parameters usually show a positive correlation (Beckman and Roberts 1995; Smith and Walker 1930). However, there are studies showing that the two parameters can be uncoupled, and disease symptoms do not always reflect the extent of vascular colonization by $F$. oxysporum (Ito et al. 2005; Thatcher et al. 2009).

Multiple factors frustrate direct evaluation of $F$. oxysporum infection in roots. To begin with, being belowground, the infection is inaccessible to direct observation. Even when roots

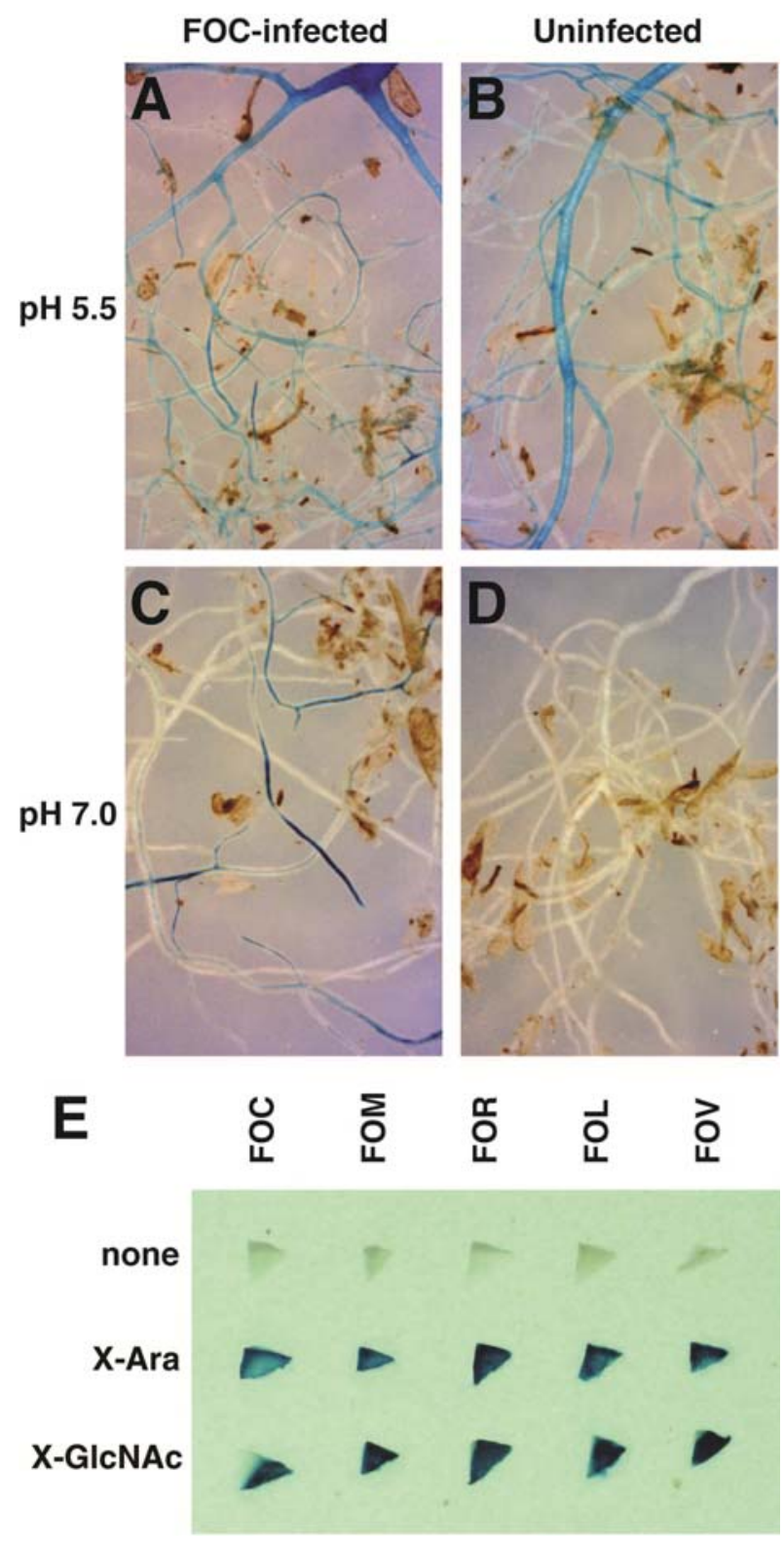

Fig. 1. 5-Bromo-4-chloro-3-indoxyl- $\alpha$-L-arabinofuranoside (X-Ara) staining in Fusarium oxysporum f. sp. conglutinans-infected roots and F. oxysporum cultures. Roots of soil-grown Arabidopsis aos plants were stained overnight with X-Ara. Roots were harvested 15 days after irrigation with $F$. oxysporum f. sp. conglutinans (FOC-infected) and stained in buffer $\mathbf{A}, \mathrm{pH} 5.5$ or $\mathbf{C}, \mathrm{pH}$ 7.0, or after irrigation with water only (uninfected) and stained in buffer $\mathbf{B}$, $\mathrm{pH} 5.5$ or D, pH 7.0. E, Agar pieces from fresh culture of five $F$. oxysporum formae speciales $-F$. oxysporum f. sp. conglutinans (FOC), F. oxysporum f. sp. mathioliv (FOM), F. oxysporum f. sp. raphani (FOR), F. oxysporum f. sp. lycopersici race 3 (FOL), and F. oxysporum f. sp. vasinfectum race 4 (FOV) - grown on $2 \%$ oat spelt xylan were stained at $\mathrm{pH} 7.0$ with X-Ara, 5-bromo-4-chloro-3-indoxyl-2-acetamido-2-deoxy- $\beta$-D-glucopyranoside (X-GlcNAc), or neither reagent (none). are isolated from soil, $F$. oxysporum, like other fungal endophytes, is not readily discerned within host tissue because $F$. oxysporum cells are colorless and sparse and are dwarfed by host cells. Histochemical stains that preferentially bind to or react with fungal constituents can accentuate fungal cells amid plant cells (Vierheilig et al. 2005). However, general histochemical stains often give inadequate intensity, specificity, or penetration for clear-cut detection. In addition, a need for technical expertise and optimization limits the general application of some histochemical procedures.

Heterologous expression of green fluorescent protein (GFP), from the jellyfish Aequorea victoria, or red fluorescent protein, from reef coral Discosoma spp., in F. oxysporum can confer an intrinsic visible fluorescence and give clear discrimination of $F$. oxysporum in plant tissue (Lagopodi et al. 2002; Olivain et al. 2006). Several groups have published vivid images of $F$. oxysporum expressing fluorescent protein in plant roots (Lagopodi et al. 2002; Olivain et al. 2006; Sarrocco et al. 2007). In a noteworthy example, Czymmek and associates (2007) captured the initial colonization of an Arabidopsis root by GFP-expressing $F$. oxysporum f. sp. conglutinans, using time-lapse photography, and reported that i) $F$. oxysporum invades the vascular system primarily from meristematic regions of root tips and lateral root primordia (LRP) and ii) a distinctive mycelial mass forms at a site where $F$. oxysporum penetrates root tips. However, although expression of fluorescent protein enhances the visibility of $F$. oxysporum mycelia in plant tissue, there are few examples showing the suitability of GFP-tagged $F$. oxysporum for enumerating $F$. oxysporum biomass in plants (Li et al. 2011; Michielse and Rep 2009).

Heterologous expression of the Escherichia coli gene uidA, which expresses $\beta$-glucuronidase (GUS) and hydrolyzes $\beta$-glucuronide substrates that are designed for colorimetric or fluorometric detection, has been used to both observe and measure fungal biomass in plants (Bao and Lazarovits 2001; Gallagher 1992; Papadopoulou et al. 2005). For example, GUS can cleave the colorless substrates 5-bromo-4-chloro-3-indoxyl- $\beta$ D-glucuronic acid (X-Gluc) to yield a visible blue precipitate. uidA was first heterologously expressed in transgenic plants but has been successfully introduced to other eukaryotes, including F. oxysporum (Couteaudier et al. 1993; Jefferson et al. 1987; Roberts et al. 1989).

However, technical considerations hinder the routine use of GFP and uidA reporter genes in F. oxysporum, as well as other endophytic fungi. Stable genetic transformation must be possible with the fungal strain that is to be tagged, and optimal reporter gene expression may require the prior testing of different gene constructs or selection of multiple transformants (Bao et al. 2000; Mullins and Kang 2001). Even when the expression of a reporter gene is established in a particular organism, the gene must be reintroduced into each tested strain.

Here, I developed a familiar methodology that uses the intrinsic glycolytic activity of $F$. oxysporum to visualize and quantify $F$. oxysporum infection in plant roots. Characterization of $F$. oxysporum infection in the roots of four Arabidopsis mutants shows that the three phases of Fusarium wilt disease are affected differently by mutations in three auxin transport-related genes, $A G B 1, E I R 1$, and TIR3, and the natural resistance gene, RFOI.

\section{RESULTS}

F. oxysporum f. sp. conglutinans-specific

5-bromo-4-chloro-3-indoxyl- $\alpha$-L-arabinofuranoside (X-Ara) and 5-bromo-4-chloro-3-indoxyl-2-acetamido-2deoxy- $\beta$-D-glucopyranoside (X-GlcNAc) staining in roots.

Incubation of $F$. oxysporum f. sp. conglutinans-infected roots with various 5-bromo-4-chloro-3-indoxyl (X) glycoside reagents 
produced visible blue staining. In total, I stained roots with 11 commercially available $\mathrm{X}$ glycosides (given in below) using a methodology that is commonly used with the X-Gluc reagent to visualize expression of uidA in transgenic plants (Jefferson et al. 1987). Because an optimal $\mathrm{pH}$ for the relevant hydrolytic activities could not be known beforehand, F. oxysporum f. sp. conglutinans-infected roots were incubated with each $\mathrm{X}$ glycoside in either acidic ( $\mathrm{pH} 5.5)$ or neutral $\mathrm{pH}$ (7.0) buffer. Dis-
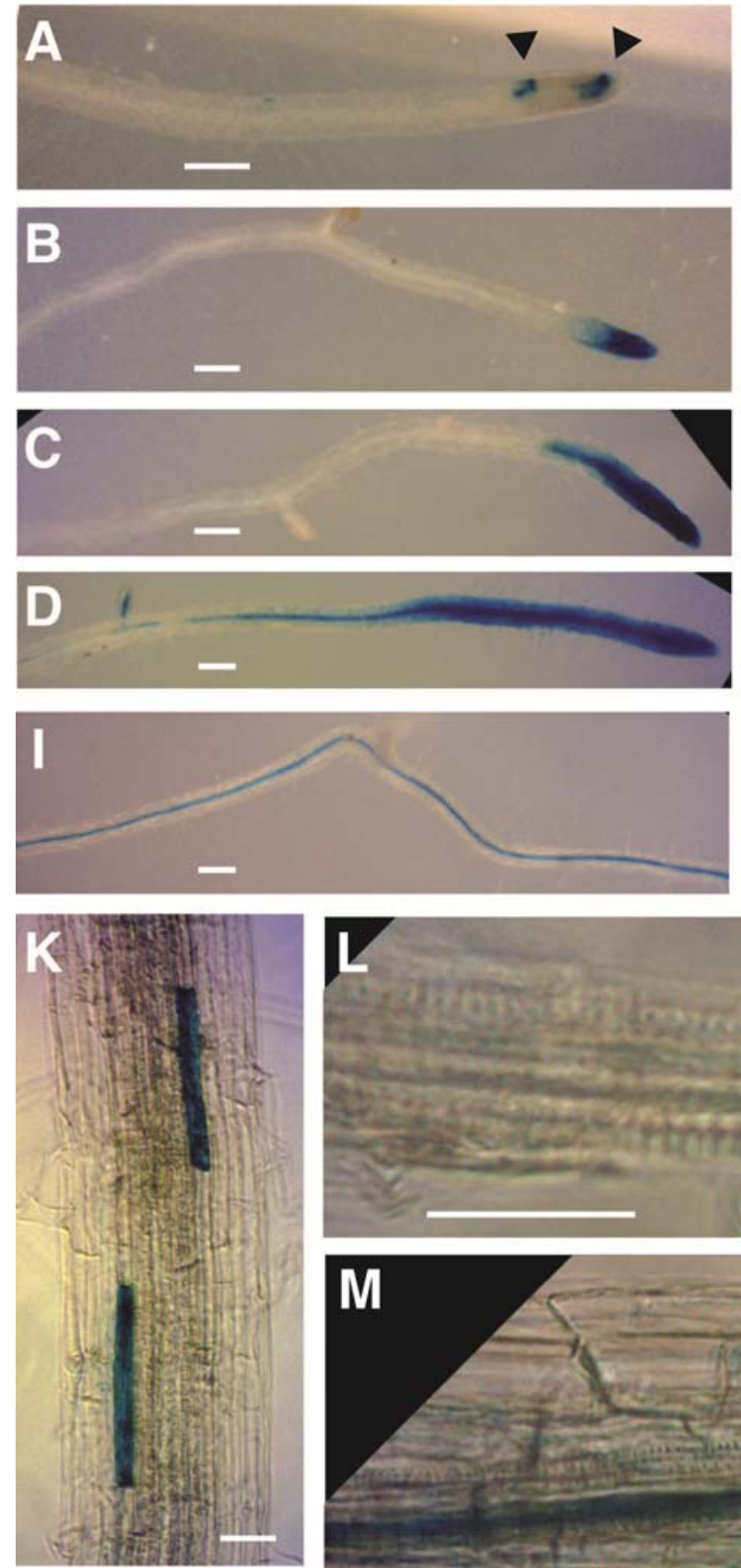
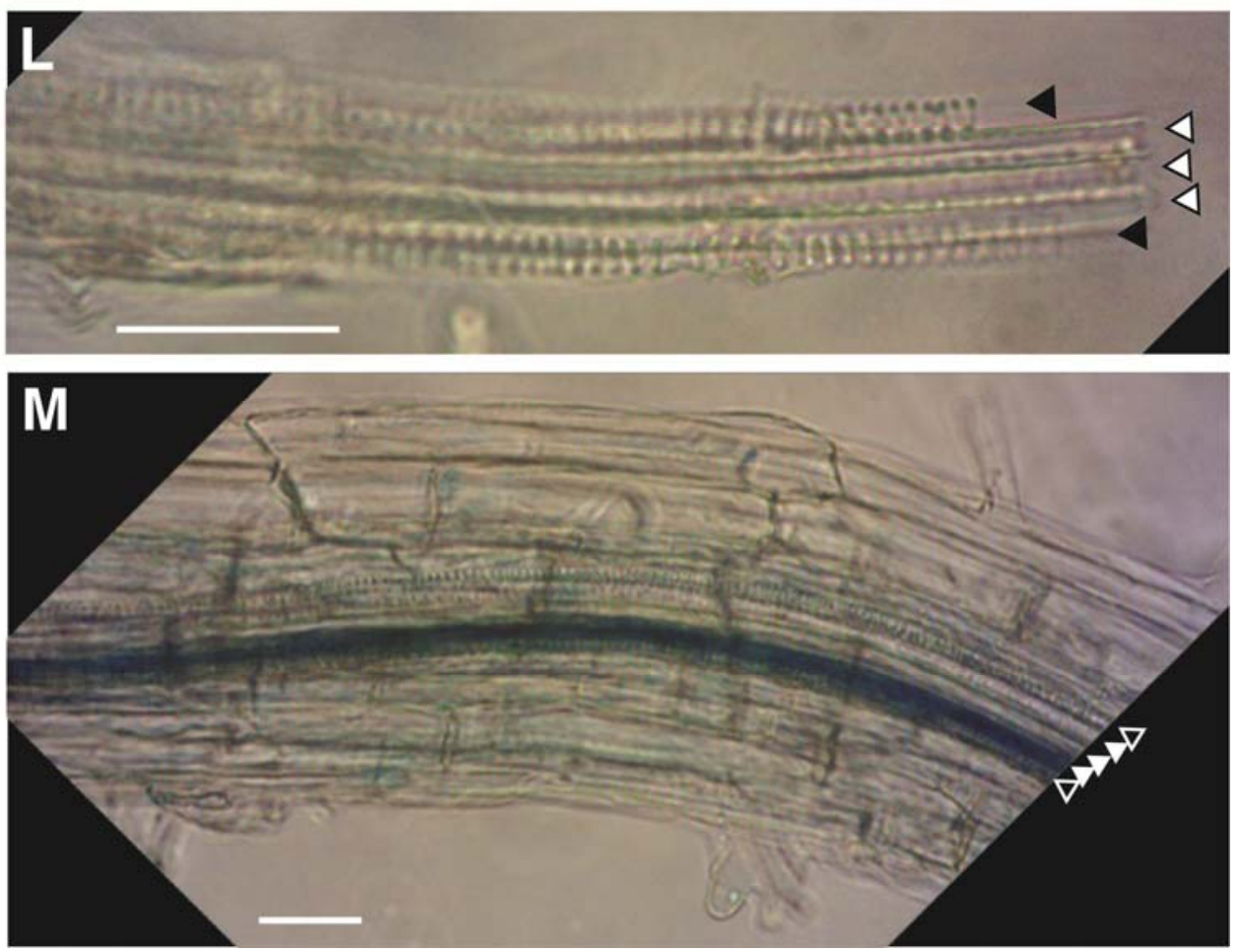

Fig. 2. Staining patterns in Fusarium oxysporum f. sp. conglutinans-infected roots. Representative 5-bromo-4-chloro-3-indoxyl- $\alpha$-L-arabinofuranoside-staining patterns seen in F. oxysporum f. sp. conglutinans-infected Arabidopsis roots: $\mathbf{A}$ to $\mathbf{D}$, at root tips and $\mathbf{E}$ to $\mathbf{H}$, lateral root primordia (LRP); $\mathbf{I}, \mathbf{J}$, and $\mathbf{M}$, in the vascular cylinder; and $\mathbf{K}$, within two isolated cells in the root epidermis. Discreet spots stain the outer apical surface of the root tip (at black triangles, A) or LRP (at white-filled triangle, E). Stain consumes the whole root tip (B) or LRP (at white-filled triangle, F). Stain extends into the vascular cylinder for a short distance from the root tip (C) or LRP (at white-filled triangle, G) or in a vascular element for a longer distance away from the root tip (D) or LRP (at white-filled triangle, H). Farther from root apices, stain is restricted to one (I) or two (J) vessels in the vascular cylinder. L, The broken end of an Arabidopsis root exposes the primary xylem, three metaxylem vessels (at white-filled triangles), and two flanking protoxylem vessels (at black triangles), because cell walls of vessels are more durable than surrounding tissues. M, Blue staining is confined to the lowest of three metaxylem vessels (white triangles) and absent from two protoxylem vessels (black-filled triangles) in the central vascular cylinder. 
tinctive patterns of blue precipitate were visible when roots were stained with 9 of the 11 reagents. In further analysis, I disregarded nine combinations of $\mathrm{X}$ glycoside and buffer $\mathrm{pH}$ $(+\mathrm{pH})$ because they produced no obvious, or too little, staining: X- $\alpha$-L-fucopyranoside $(+5.5$, or +7.0$), X-\alpha-D-x y l o p y r a n o s i d e$ $(+5.5$, or +7.0$), \mathrm{X}-N$-acetyl- $\beta$-D-galactosaminide $(+5.5$, or +7.0$)$,
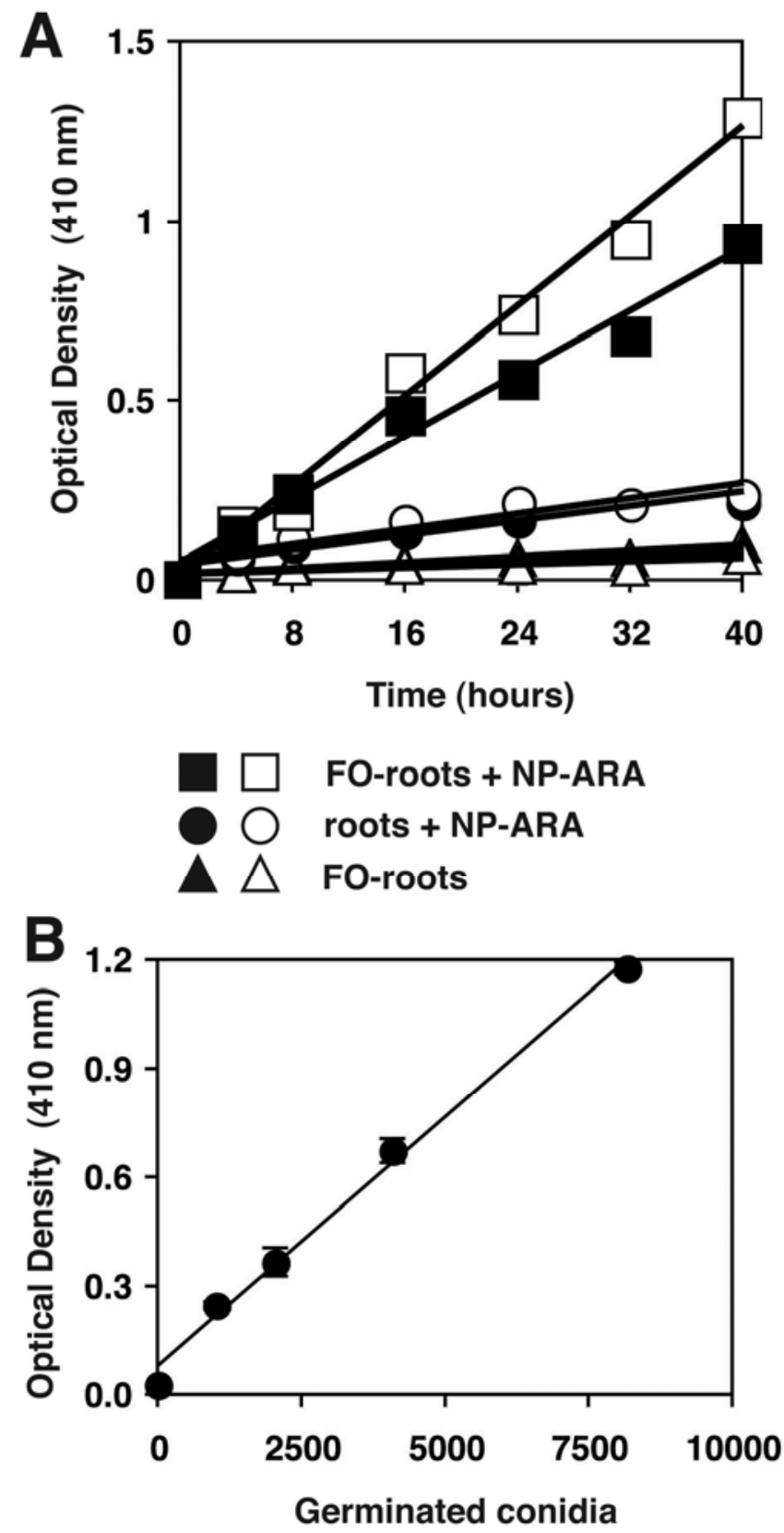

Fig. 3. In situ arabinofuranosidase (ARA) activity in Fusarium oxysporum f. sp. conglutinans (FO)-infected roots. A, Optical density at $410 \mathrm{~nm}$ was measured at regular times after the addition of freshly harvested roots to incubation buffer at neutral $\mathrm{pH}$. There are two representative plants (open and filled symbols) for each treatment: Roots were from an $F$. oxysporum f. sp. conglutinans-infected plant, and buffer included 4-nitrophenyl- $\alpha$-Larabinofuranoside (NP-ARA; squares). Roots were from an uninfected plant, and buffer included NP-ARA (circles). Roots were from an F. oxysporum f. sp. conglutinans-infected plant, and buffer did not include a glycoside reagent (triangles). B, Optical density at $410 \mathrm{~nm}$ was measured for a serial dilution of germinated $F$. oxysporum $\mathrm{f}$. sp. conglutinans conidia incubated with NP-ARA at neutral $\mathrm{pH}$. Estimated number of conidia on agar plugs is indicated below the graph. Values are the mean of three sample, and error bars are the confidence interval of the mean $(\alpha=0.05)$. Line is from linear regression of sample data $\left(R^{2}=0.99\right)$.
X- $\beta$-D-cellobioside (+7.0), X- $\beta$-D-galactopyranoside (+7.0), or X-Gluc (+7.0).

Staining with two of nine $\mathrm{X}$ glycosides was specifically associated with $F$. oxysporum f. sp. conglutinans infection. For the sake of comparison, I incubated $F$. oxysporum f. sp. conglutinans-infected and mock-infected roots side by side. Eleven combinations of $\mathrm{X}$ glycoside reagent and buffer $\mathrm{pH}$ produced indistinguishable staining patterns in infected and uninfected roots. In acidic buffer, staining with X-Ara (or X-GlcNAc) was more or less the same in infected (Fig. 1A) and uninfected (Fig. 1B) roots whereas, in neutral buffer, only $F$. oxysporum f. sp. conglutinans-infected roots (Fig. 1C) were stained blue by $\mathrm{X}$-Ara (or X-GlcNAc). In subsequent experiments, infectionspecific staining with X-GlcNAc proved to be more reliable in buffer that was slightly acidic ( $\mathrm{pH}$ 6.8) than in buffer at neutral $\mathrm{pH}$.

The above staining trials were performed with roots of the jasmonate (JA)-deficient mutant aos to account for two hypothetical concerns (my motives are discussed below) (Park et al. 2002). Nevertheless, when staining with X-Ara or X-GlcNAc was repeated with wild-type roots, results were no different from results obtained with aos roots. Thus, host biosynthesis of JA was inconsequential for the infection-specific arabinofuranosidase $(\mathrm{ABF})$ and $N$-acetyl-glucosaminidase (NAG) activities.

F. oxysporum, and not the host plant, was the source of ABF and NAG activities in $F$. oxysporum f. sp. conglutinans-infected roots. At neutral $\mathrm{pH}$, uninfected Arabidopsis roots have never yielded appreciable staining with X-Ara (Fig. 1D) or XGlcNAc. On the other hand, axenic fungal cultures of various $F$. oxysporum formae speciales, including $F$. oxysporum f. sp. conglutinans, turned blue when incubated in buffer conditions that gave $F$. oxysporum f. sp. conglutinans-specific staining in roots (Fig. 1E). Furthermore, blue staining of agar plate cultures indicated that ABF and NAG activities were expressed by most formae speciales growing on minimal medium with a simple carbon source, either glucose, galactose, sucrose, or xylose; and, for all formae speciales, the strongest staining was attained in medium supplemented with a complex hemicellulose, xylan (Fig. 1E).

\section{Common patterns of staining}

in $\boldsymbol{F}$. oxysporum f. sp. conglutinans-infected roots.

Incubation of $F$. oxysporum f. sp. conglutinans-infected roots with X-Ara or X-GlcNAc produced staining that matched prior histological descriptions of $F$. oxysporum infection (Czymmek et al. 2007; Smith and Walker 1930; Turlier et al. 1994). Only a fraction of branches in the root system were stained blue, which is consistent with $F$. oxysporum $\mathrm{f}$. sp. conglutinans infection being only present in a subset of branches of the root system. In contrast, staining with other X glycosides was typically uniform and associated with particular tissues or developmental stages throughout the root system. Strongest staining was located at root tips (Fig. 2A to D) and at LRP (Fig. 2E to H). Away from root tips and LRP, staining was usually confined to the central vascular cylinder (Fig. 2C, $\mathrm{D}$, and $\mathrm{G}$ to $\mathrm{J}$ ). Sometimes individual cells on the root surface were stained blue (Fig. 2K). A similar isolated colonization of epidermal cells by fluorescent protein-tagged $F$. oxysporum $\mathrm{f}$. sp. lycopersici is observed in infected tomato roots as well (van der Does et al. 2008).

A typical course of infection was discerned in the recurring patterns that I observed in stained $F$. oxysporum f. sp. conglutinans-infected roots. Marking the start of the primary determinative phase, the subtlest staining was seen at the outer cell layers of the root apex (Fig. 2A) or atop an emerging LRP in the gap between detaching epidermal and cortical cells (Fig. 2E, 

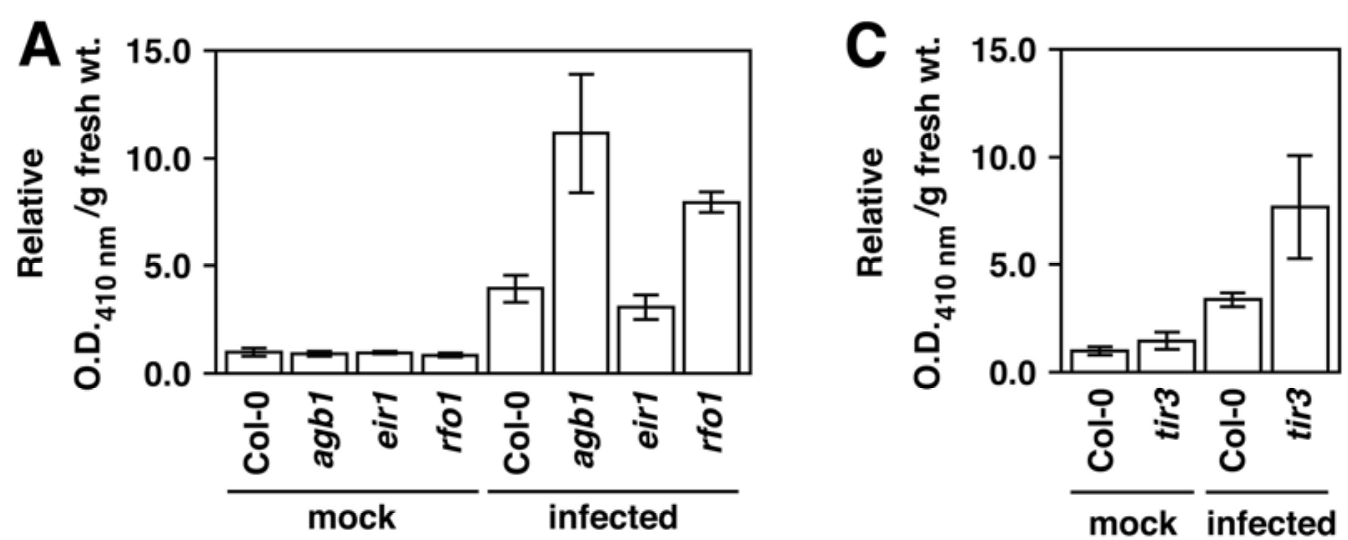

B
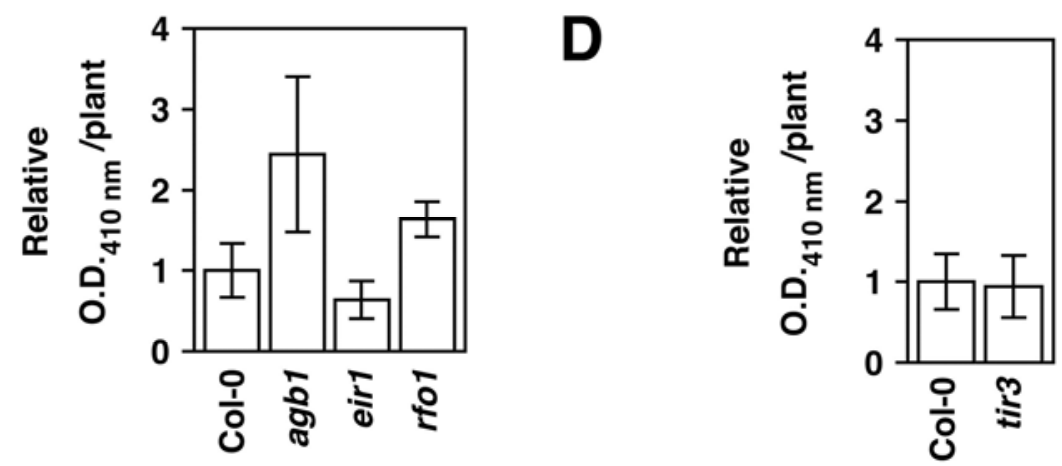

Fig. 4. Quantification of Fusarium oxysporum f. sp. conglutinans infection in Arabidopsis mutants. Freshly harvested roots of individual plants, uninfected (mock) or infected, were incubated with 4-nitrophenyl- $\alpha$-L-arabinofuranoside. Optical density (O.D.) of buffer, incubated at constant grams fresh weight per liter of buffer, was measured at $410 \mathrm{~nm}$. A and B, Wild type (Columbia-0 [Col-0]) mock $(n=3)$ and infected $(n=4), a g b 1 \mathrm{mock}(n=3)$ and infected $(n=3)$, eirl mock $(n=3)$ and infected $(n=4)$, and $r f o l$ mock $(n=3)$ and infected $(n=4)$. $\mathbf{C}$ and $\mathbf{D}$, Col- 0 mock $(n=3)$ and infected $(n=3)$, and $\operatorname{tir} 3$ mock $(n=3)$ and infected $(n=3)$. Values of individual plants were also expressed as O.D. per plant (in B and D). Mean values were adjusted to give treated Col-0 roots (A and C) or infected Col-0 (B and D) a value of 1. Error bars are the confidence interval of the mean $(\alpha=0.05)$.

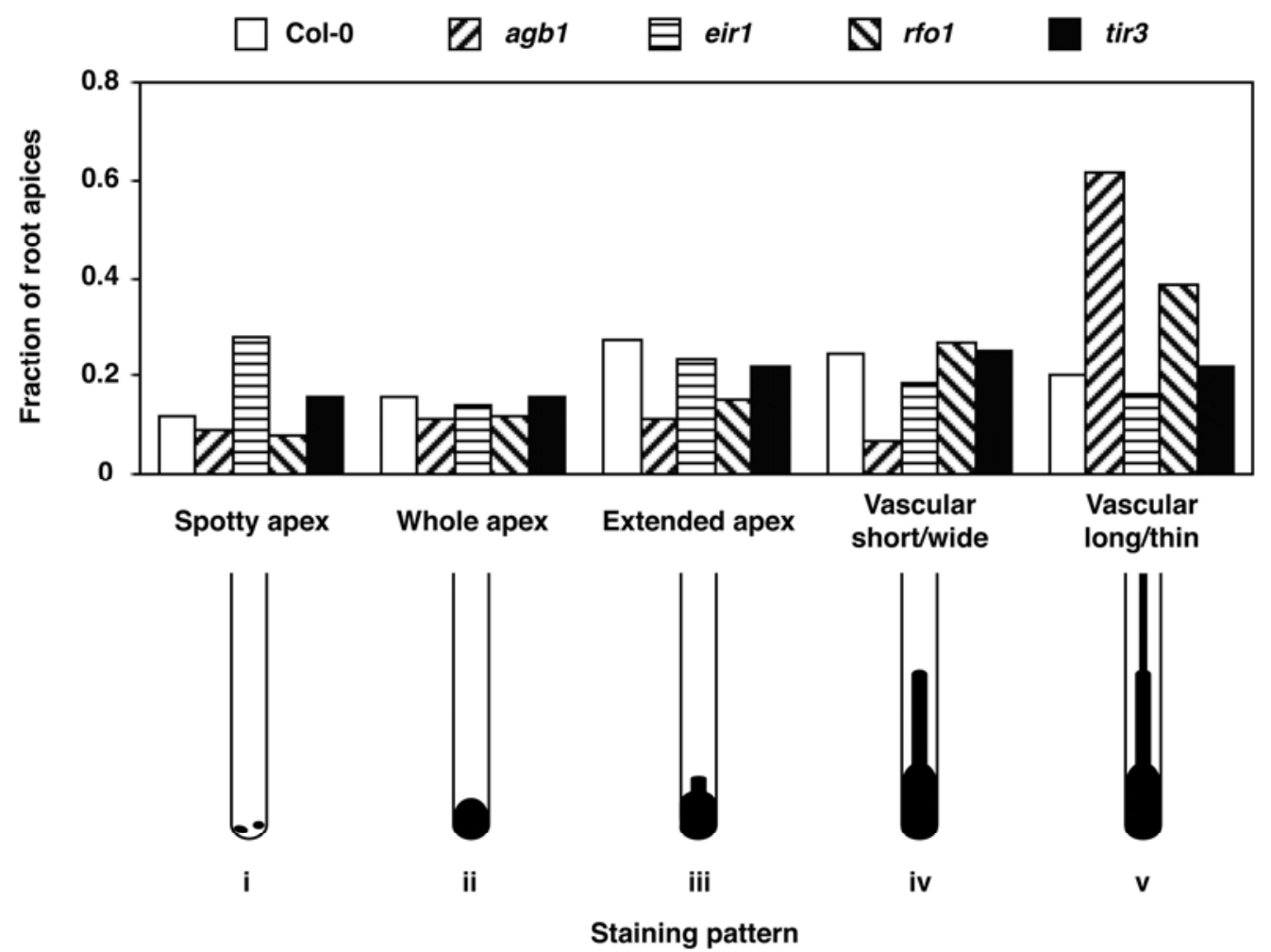

Fig. 5. Distribution of staining patterns at root apices. Root apices of Fusarium oxysporum f. sp. conglutinans-infected plants were assigned to five categories of 5-bromo-4-chloro-3-indoxyl-arabinofuranosidase staining, depicted below the graph. Staining at the apex i) was in discreet spots or ii) the whole meristematic region; or extended into iii) mature tissues, iv) the vascular cylinder, indiscriminately, for short distances, or (v) specific vascular elements for longer distances. Bars indicate the fraction of stained root apices with a particular staining pattern. Root apices from the whole root systems of two plants represent each genotype: wild type (Columbia-0 [Col-0]), $n=137 ;$ agb1, $n=88 ;$ eirl, $n=85 ;$ rfol, $n=104$; and, tir3, $n=64$. 
at triangle) where Czymmek and associates (2007) observed initial $F$. oxysporum f. sp. conglutinans penetration. After initial penetration of root apices, staining became indiscriminate and thoroughly covered the meristematic region of the root apex (Fig. 2B), or the whole LRP (Fig. 2F). When root tips were consumed by $F$. oxysporum f. sp. conglutinans infection, staining extended into more basal, mature tissue and, in particular, the vascular cylinder (Fig. $2 \mathrm{C}$ and $\mathrm{G}$ ). In a transition that presumably signifies the transition from the primary to secondary determinative phase, further staining away from the root tip (Fig. 2D) or LRP (Fig. 2H) was largely confined to the vascular cylinder. In the secondary determinative phase, $F$. oxysporum f. sp. conglutinans made more extensive inroads into the root system, as indicated by one (Fig. 2I) or two (Fig. 2J) fine blue lines that pass through the central vascular cylinder. Interestingly, many root tips were thoroughly stained blue, whereas fine vascular staining extended from only a fraction of these $F$. oxysporum f. sp. conglutinans-colonized root tips. This suggested that $F$. oxysporum infection did not always make the transition from the primary to secondary determinative phase or that the host applied stronger opposition to $F$. oxysporum infection in the secondary determinative phase.

On closer inspection, the fine vascular staining tracked with xylem vessels (Dolan et al. 1993). During primary root growth, the xylem, isolated from other root tissues (Fig. 2L), looks like a ribbon cable and is typically composed of three central metaxylem vessels (Fig. 2L, at white-filled triangles) and two flanking protoxylem vessels (Fig. 2L, at black-filled triangles). In one example of a root with fine vascular staining, a single metaxylem vessel (Fig. 2M, at the lowest white-filled triangle) was filled with blue precipitate. Occasionally, two separate vessels were infected simultaneously and appeared as parallel blue line (Fig. 2J).

\section{Quantification of $F$. oxysporum f. sp. conglutinans infection in Arabidopsis mutants.}

To quantify the $F$. oxysporum infection, I measured ABF activity in F. oxysporum f. sp. conglutinans-infected roots. When
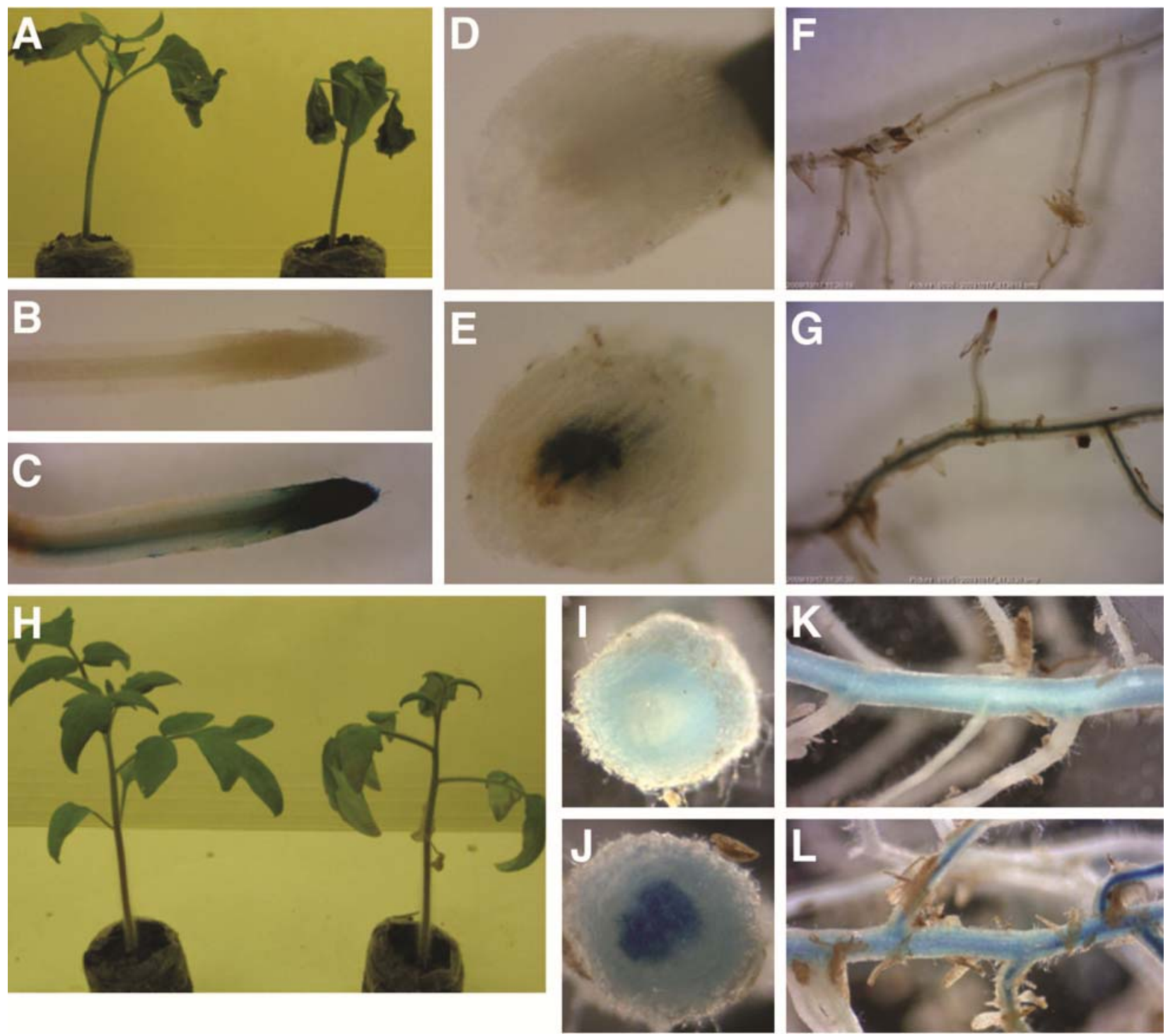

Fig. 6. 5-Bromo-4-chloro-3-indoxyl- $\alpha$-L-arabinofuranoside (X-Ara) staining in Fusarium oxysporum $\mathrm{f}$. sp. vasinfectum-infected cotton and F. oxysporum $\mathrm{f}$. sp. lycopersici-infected tomato. A, Wilt symptoms appear in cotton seedling, 10 days after soil was irrigated with water (on left) or with $F$. oxysporum $\mathrm{f}$. sp. vasinfectum (on right). Roots of cotton seedlings were stained with X-Ara $\mathbf{B}, \mathbf{D}$, and $\mathbf{F}$, after mock infection or $\mathbf{C}, \mathbf{E}$, and $\mathbf{G}$, after infection with $F$. oxysporum f. sp. vasinfectum. B and $\mathbf{C}$, Root tips, 4 days after infection; $\mathbf{D}$ and $\mathbf{E}$, root cross-section, 10 days after infection; and $\mathbf{F}$ and $\mathbf{G}$, root with lateral roots, 10 days after infection. $\mathbf{H}$, Wilt symptoms appear in tomato seedling, 10 days after soil was irrigated with water (on left) or with $F$. oxysporum f. sp. lycopersici (on right). Roots of tomato seedlings were stained with X-Ara $\mathbf{I}$ and $\mathbf{K}$, after mock infection or $\mathbf{J}$ and $\mathbf{L}$, after infection with $F$. oxysporum f. sp. vasinfectum. I and $\mathbf{J}$, Root cross-section, 10 days after infection; and $\mathbf{K}$ and $\mathbf{L}$, root with lateral roots, 10 days after infection. 
the colorless substrate 4-nitrophenyl- $\alpha$-L-arabinofuranoside (NP-Ara) is hydrolyzed, soluble yellow 4-nitrophenol is produced (Panagiotou et al. 2003). When F. oxysporum f. sp. conglutinans-infected and uninfected roots were incubated with an excess of NP-Ara, roughly fivefold more blue light $(410 \mathrm{~nm})$ was absorbed in buffer from incubation with $F$. oxysporum $\mathrm{f}$. sp. conglutinans-infected roots than uninfected roots (Fig. 3A). Accumulation of 4-nitrophenol accounted for the increased absorbance at $410 \mathrm{~nm}$ because yellow pigment did not accumulate when $F$. oxysporum-infected roots were incubated in buffer without NP-Ara (Fig. 3A). During the 40-h incubation, ABF activity appeared to be quite stable as the accumulation of 4-nitrophenol approximated a linear rate (Fig. 3A). Furthermore, $\mathrm{ABF}$ activity in terms of absorbance, or optical density, at $410 \mathrm{~nm}\left(\mathrm{OD}_{410 \mathrm{~nm}}\right)$ was proportional to fungal biomass when a serial dilution of $F$. oxysporum $\mathrm{f}$. sp. conglutinans in agar plugs was similarly incubated with NP-Ara (Fig. 3B).

Using the NP-Ara assay, I quantified $F$. oxysporum $\mathrm{f}$. sp. conglutinans infection in roots of wild-type Arabidopsis and mutants agbl, eirl, rfol, and tir3. For each measurement, I harvested the root system of a single plant 7 days after soil was infected with $F$. oxysporum $\mathrm{f}$. sp. conglutinans, at a time when wild-type plants were exhibiting only early, subtle symptoms, such as leaf epinasty, stunting of petioles, and accumulation of anthocyanin. Because $\mathrm{ABF}$ activity was related to $\mathrm{OD}_{410 \mathrm{~nm}}$ of the incubation buffer (Fig. 3), I determined and expressed the amount of $\mathrm{ABF}$ activity per gram fresh weight of roots as the $\mathrm{OD}_{410 \mathrm{~nm}}$ per gram fresh weigh of roots (Fig. 4A and C). By taking into account the total fresh weight of a root system, I also expressed the total ABF activity in an F. oxysporum $\mathrm{f}$. sp. conglutinans-infected plant as the $\mathrm{OD}_{410 \mathrm{~nm}}$ per plant (Fig. $4 \mathrm{~B}$ and D).

Based on the severity of foliar symptoms in the expressive phase, previous studies concluded that $a g b l$ and $r f o l$ were more susceptible and eirl and tir3 more resistant to $F$. oxysporum $\mathrm{f}$. sp. conglutinans than the wild type (Diener and Ausubel 2005; Kidd et al. 2011; Trusov et al. 2006). With the exception of tir3, the relative $\mathrm{ABF}$ activity $\left(\mathrm{OD}_{410 \mathrm{~nm}}\right.$ per gram fresh weight) in $F$. oxysporum f. sp. conglutinans-infected mutants agreed with these published expectations (Fig. 4A and C). For all genotypes, infected roots had substantially higher levels of ABF activity than uninfected roots, which yielded similar low values (Fig. 4A and $\mathrm{C})$. ABF activity in $r f o l$ and $a g b l$ was twofold and threefold higher, respectively, than in the wild type (Fig. 4A). ABF activity in eirl roots was three-quarters of that in the wild-type roots (Fig. 4A); therefore, the tendency in F. oxysporum infection matched the reduced symptom development that is observed in eirl (Kidd et al. 2011), and the corresponding one-tailed $P$ value of 0.044 was significant. Because the fresh weights of $a g b l$, eirl, and rfol root systems were comparable with the fresh weight of the wild-type root system, comparisons of total ABF activity per plant (Fig. 4B) led to the same conclusions as the above analysis of ABF activity per gram fresh weight (Fig. 4A). Similar differences in ABF activity of $F$. oxysporum f. sp. conglutinans-infected wild-type and mutant roots were also obtained in an independent experiment (Supplementary Fig. S1A and $\mathrm{B})$.

Paradoxically, tir3, which was characterized as highly resistant to $F$. oxysporum f. sp. conglutinans and, thus, expected to contain much less ABF activity than the wild type (Kidd et al. 2011), instead had 2.6-fold more ABF activity per gram fresh weight in $F$. oxysporum-infected roots than the wild type (Fig. 4C). However, the tir3 mutation also severely restricts overall growth, including root growth, and the mean fresh weight of harvested wild-type root systems was 2.4-fold greater than the corresponding tir3 root system (Ruegger et al. 1997); furthermore, this difference likely underestimates the growth defi- ciency of tir3 because I chose, for F. oxysporum infection, those tir3 plants with better growth. Arguably, the same rate of F. oxysporum infection managed to occupy more of the abbreviated tir3 root system than the much larger wild-type root system. Consistent with this interpretation, the total ABF activity $\left(\mathrm{OD}_{410 \mathrm{~nm}}\right.$ per plant) in tir3 roots was essentially the same as in wild-type roots (Fig. 4D), which suggests that $F$. oxysporum infection in roots was unchanged by the tir 3 mutation.

\section{Distribution of X-Ara staining patterns in Arabidopsis mutants.}

Staining $F$. oxysporum f. sp. conglutinans-infected roots with X-Ara corroborated the quantitative results that I obtained with NP-Ara. Importantly, root apices and the central vascular cylinder of tir3 roots had extensive blue staining, showing that colonization of tir3 roots by $F$. oxysporum had a normal appearance. Compared with the wild type, more of the agbl and $r f o l$ root systems appeared to have strong vascular staining, whereas fewer root ends in the eirl root system had blue staining.

To appreciate which phases of the infection cycle were affected in Arabidopsis mutants, I quantified the staining patterns that were observed at root apices and compared the distributions of patterns from different genotypes. Blue-stained root apices were assigned to one of five categories, representing commonly observed patterns (Fig. 5). In a typical progression of the infection cycle, the first two (i and ii) and last two (iv and v) categories would correspond to stages in the primary and secondary determinative phases while a transition between the determinative phases would be associated with the middle category iii (Beckman 1987). For each genotype, I evaluated all stained root apices in two whole $F$. oxysporum f. sp. conglutinans-infected root systems (Fig. 5). In the wild type, the fraction of root apices represented by each category was 12 to $28 \%$ and, in the largest category (iii), blue staining extended somewhat beyond the root apex but not exclusively in the vascular cylinder. In contrast, 61 and 39\% of agbl and rfol root apices, respectively, had progressed to a late stage of the secondary determinative phase (category v). In fact, these percentages are conservative estimates for agbl and rfol because staining that joined multiple root apices was only counted once, which may explain why fewer stained root apices in total were counted in agbl $(n=88)$ and $r f o l(n=104)$ roots than in the wild type $(n=137)$. In eirl, fewer root apices $(n=85)$ had blue staining, and category i, which represents $F$. oxysporum infection at an early stage of the primary determinative phase, had the most eirl root apices (28\%). Only $12 \%$ of wild-type roots had a similar limited staining at the apex. On the other hand, the distribution of staining patterns at root apices in tir3 and the wild type were remarkably similar. Consistent differences in staining of wild-type and mutant apices were observed in an independent experiment.

\section{Staining of plant roots infected with other formae speciales.}

$\mathrm{X}$-Ara staining was successfully applied to other $F$. oxysporum pathosystems. Other formae speciales, including $F$. oxysporum f. sp. mathioli, F. oxysporum f. sp. raphani, F. oxysporum f. sp. lycopersici, and $F$. oxysporum f. sp. vasinfectum, expressed ABF activity in axenic culture (Fig. 1E). Blue staining in $F$. oxysporum f. sp. mathioli-infected and $F$. oxysporum f. sp. raphani-infected Arabidopsis roots mirrored the patterns already described in $F$. oxysporum $\mathrm{f}$. sp. conglutinans-infected roots. In seedlings of cotton (Fig. 6A) and tomato (Fig. 6H) that showed wilt symptoms, blue precipitate developed in $F$. oxysporum f. sp. vasinfectum-infected roots (Fig. 6C, E, and $\mathrm{G}$ ) and $F$. oxysporum f. sp. lycopersici-infected roots (Fig. 6J and $\mathrm{L}$ ) after incubation with $\mathrm{X}$-Ara. In particular, intense blue 
staining was seen at root tips (Fig. C) and in the vascular cylinder (Fig. 6E and J). In contrast, no vascular staining was evident in roots of mock-infected cotton (Fig. 6D and F) or tomato (Fig. 6I and K). A faint blue staining in cortical tissue outside the central vascular cylinder was evident in both infected (Fig. $6 \mathrm{~J}$ and L) and uninfected tomato roots (Fig. 6I and K).

\section{DISCUSSION}

For plant biologists, staining plant tissue with X-Ara and XGlcNAc should be familiar because transgenic plants are commonly stained with X-Gluc, in a similar fashion, to detect the widely used reporter gene uidA (Gallagher 1992; Jefferson et al. 1987). uidA has also been used as a reporter gene in filamentous fungi, including $F$. oxysporum (Roberts et al. 1989); and others have reported the use of $F$. oxysporum-expressed GUS to localize and quantify $F$. oxysporum in roots (Bao and Lazarovits 2001; Papadopoulou et al. 2005). Initially, I also transformed $F$. oxysporum f. sp. conglutinans with uidA but found GUS expression to be inadequate for clear and thorough visualization of F. oxysporum f. sp. conglutinans in Arabidopsis roots, even though my staining of GUS-expressing $F$. oxysporum in roots was comparable with published examples (Bao and Lazarovits 2001; Roberts et al. 1989). I could have worked on optimizing the expression of uidA in F. oxysporum; however, considering that $F$. oxysporum has 555 genes that express carbohydrate-active enzymes (Ma et al. 2010), I instead screened for a glycolytic activity that is strongly expressed by $F$. oxysporum during infection but not by the plant host. In fact, Arabidopsis does express detectable ABF and NAG in acidic buffer (Fig. 1B) but not at neutral pH (Fig. 1D). Similarly, AtGUS2 encodes an endogenous GUS activity in Arabidopsis that accounts for faint X-Gluc staining in acidic buffer; nevertheless, transgenic uidA is a common reporter gene in plants because there is no appreciable endogenous GUS activity at neutral pH (Eudes et al. 2008). At neutral pH, F. oxysporum-derived ABF activity in roots is strong and stable enough to quantify $F$. oxysporum infection in situ with a simple spectrophotometric measurement, the absorbance of 4-nitrophenol in incubation buffer (Panagiotou et al. 2003).

Staining for ABF in tomato and cotton shows that the same or a similar approach could have wider application. On the one hand, I only tested $F$. oxysporum-infected roots with X-Ara and X-GlcNAc; therefore, the same methodology might be used to visualize other endophytic fungi, oomycetes, or bacteria. On the other hand, if staining with X-Ara or X-GlcNAc were somewhat specific for $F$. oxysporum, this methodology could be used to detect $F$. oxysporum in plants from the field as well. Furthermore, for endophytes that are not easily transformed with a heterologous reporter gene, such as obligate biotrophic fungi, a similar screen for infection-specific X glycoside stain should be considered (Lawrence et al. 2010).

I conducted the initial staining trials in the aos mutant to account for two hypothetical effects of endogenous JA. For one, I expected that cleaning soil from roots would induce JA-regulated wound responses that might mask or interfere with the relevant hydrolytic activities in the screen (Park et al. 2002). For the other, F. oxysporum f. sp. conglutinans is known to produce a JA-like activity (Thatcher et al. 2009), and, if JA were to induce the relevant hydrolytic activities, $F$. oxysporum f. sp. conglutinans might be detected indirectly for this JA-like activity. However, endogenous JA had no effect on the relevant $\mathrm{ABF}$ and NAG activities.

When I compared root systems of $a g b l$ and the wild type 8 days after irrigating soil with $F$. oxysporum f. sp. conglutinans, agbl had threefold more $F$. oxysporum infection than the wild type. Furthermore, the overabundance of staining patterns in category $\mathrm{v}$ in agbl suggests that $F$. oxysporum colonized the vascular cylinder rapidly and almost invariably after it colonized root tips. In comparison, wild-type roots had a broad distribution of staining patterns, which argues that the Columbia0 (Col-0) accession usually delays or even arrests $F$. oxysporum infection before $F$. oxysporum colonizes the vascular cylinder. Alternative scenarios could explain the $a g b l$ phenotype. In one, $A G B 1$ normally mediates the expression of a critical barrier to root colonization in Col-0, which is why this accession has partial wilt disease resistance. However, in the other scenario, I cannot exclude the possibility that the agbl mutation creates an abnormal metabolism that is conducive for growth of $F$. oxysporum in the vascular cylinder, and this mutant condition allows $F$. oxysporum to bypass barriers that normally restrict growth in the vascular cylinder.

As the sole $\beta$ subunit of the heterotrimeric G protein in Arabidopsis, AGB1 is expected to function in diverse extracellular signaling processes (Temple and Jones 2007). Indeed, agbl expresses pleiotropy, having a variety of seemingly unrelated morphological, physiological, and hormone-related phenotypes (Chakravorty et al. 2012). Moreover, $a g b l$ is more susceptible to diseases caused by virulent microbial pathogens Agrobacterium tumefaciens, Alternaria brassicicola, Botrytis cinerea, $F$. oxysporum, and Plectosphaerella cucumerina, as well as to penetration by nonhost fungus Magnaporthe oryzae (Ishikawa 2009; Llorente et al. 2005; Maeda et al. 2009; Trusov et al. 2006, 2009). Nevertheless, agbl remains no more susceptible than the wild type to another virulent bacterium, Pseudomonas syringae (Trusov et al. 2006). Considering that agbl could affect a number of signaling processes, it remains to be determined whether an $A G B 1$-dependent process that accounts for susceptibility to $F$. oxysporum is also responsible for agbl's susceptibility to other disease syndromes.

Kidd and associates (2011) reported that eirl exhibits less severe wilt symptoms than the wild type. Indeed, I found that eirl reduced infection in the root system by approximately one-quarter, that fewer tips in the root system of eirl had appreciable staining, and that a disproportionate fraction of infected roots in eirl had only spotty apical staining. Nevertheless, F. oxysporum wholly colonized many infected tips of eirl, and the distribution of staining patterns in eirl and the wild type was similar among roots with fully colonized apices. Thus, eirl appeared to perturb the penetration and initial colonization of root apices by $F$. oxysporum but had no clear effect on $F$. oxysporum's colonization of the vascular cylinder. Coincidentally, strong expression of EIR1 is confined to the root tip in tissues outside of the vascular cylinder (Sieberer et al. 2000). More specifically, EIR1 is located in the cortex and epidermis of the distal elongation zone as well as in epidermal cells and lateral root cap cells covering the root apex.

The root tip of eirl has normal cellular organization but is agravitropic because EIR1, an auxin efflux carrier, establishes, in response to gravity, an asymmetric distribution of auxin in the elongation zone which, in turn, responds with asymmetric growth and, thus, bends the root tip toward the gravity vector (Luschnig et al. 1998; Sieberer et al. 2000). As pointed out by Kidd and associates (2011), F. oxysporum f. sp. conglutinans may be manipulating the auxin transport function of EIR1 in its interaction with Arabidopsis and, therefore, eirl would eliminate a target for $F$. oxysporum f. sp. conglutinans-expressed virulence. However, auxin abnormally accumulates at eirl root tips (Boonsirichai et al. 2003); therefore, resistance could be the result of an unnatural mutant phenotype, if unusually high levels of auxin at root tips were incompatible with $F$. oxysporum infection.

Natural variation at $R F O 1$ contributes to the diverse responses of Arabidopsis accessions to F. oxysporum (Diener and Ausubel 
2005). Most accessions, including Col-0, have an intermediate, or partial, resistance to $F$. oxysporum $\mathrm{f}$. sp. conglutinans. I previously showed that $r f o l$, like the susceptible allele from accession Ty-0, expresses more severe disease symptoms in response to virulent pathogens $F$. oxysporum f. sp. conglutinans, $F$. oxysporum f. sp. raphani, and $F$. oxysporum f. sp. mathioli. Here, I found that $r f o l$ supported twice as much $F$. oxysporum infection as the wild type and that more $F$. oxysporum-infected roots of rfol had extensive vascular staining than roots of wild type. Thus, the natural resistance, conferred by resistant alleles of RFO1, curtailed the growth of F. oxysporum f. sp. conglutinans in the vascular cylinder. Early experiments performed by J. C. Walker and colleagues showed that resistance to $F$. oxysporum $\mathrm{f}$. sp. conglutinans among cabbage varieties correlates with the extent of vascular colonization (Smith and Walker 1930). However, in their time-lapse documentation of $F$. oxysporum infection in Arabidopsis, Czymmek and associates (2007) failed to notice a difference in the early root colonization of accessions that were highly susceptible (Cvi-0) and resistant (Gre-0) and, instead, attributed resistance in Gre- 0 to a difference in the superficial colonization of root surfaces. Possibly, natural resistance can act at multiple phases in the infection cycle.

Recently, Kazan and Manners (2009) reported that tir3 confers strong resistance to $F$. oxysporum f. sp. conglutinans (Kidd et al. 2011). My results suggest that tir3, more specifically, suppresses wilt disease symptoms because tir3 roots were not appreciably more or less resistant to $F$. oxysporum infection than the wild type. In fact, in terms of ARA activity per fresh root weight, there was two to three times more $F$. oxysporum infection in tir3 roots than wild-type roots.

The pleiotropic tir3/big/docl/asal/ga6 has morphological, physiological, and hormone-related defects, though most of these phenotypes are attributed to altered polar auxin transport (Kanyuka et al. 2003). Abnormally high levels of auxin, socalled hyperauxiny, have been implicated in the symptom development of most vascular disease syndromes (Mace et al. 1981). Arabidopsis expresses foliar symptoms in the absence of pathogen in the aboveground shoot because $F$. oxysporum infection remains belowground in the root system until late in the infection cycle (Thatcher et al. 2009). Thus, the tir3 shoot shows a remarkable tolerance for a highly infected root system, and this suggests that wilt symptoms are, at least in part, a response to $F$. oxysporum infection and not necessarily a consequence of loss of water- and nutrient-conducting root mass. Presumably, the defect in polar auxin transport in tir3 disrupts the expression of hyperauxiny that promotes shoot symptoms.

As exemplified here, future genetic analysis of Fusarium wilt will benefit from assays that quantify $F$. oxysporum infection in roots. By incorporating multiple phenotypic parameters in the analysis of Arabidopsis mutants, I was able to associate the normal functions of mutated genes with particular phases in vascular wilt disease (Fig. 7). Thus, the analysis revealed that $A G B 1$ suppresses $F$. oxysporum's entry and colonization of the vascular cylinder, EIRl promotes the penetration and initial colonization of root apices, $R F O 1$ suppresses $F$. oxysporum colonization of xylem vessels, and TIR3 promotes symptom development in the shoot. Notably, three mutants - agb1, eirl, and tir3 - that share a common association with basipetal auxin transport appear to mostly affect different phases of the infection cycle.

\section{MATERIALS AND METHODS}

Plant and $F$. oxysporum stocks, growing conditions, and infection.

I obtained Arabidopsis mutants, in the Col-0 genetic background, agb1-1 (CS3976), aos (SALK_017756C), eirl-1
(CS8058), rfol (SALK_077975, Diener and Ausubel 2005), and tir3-101 (CS3928) from the Arabidopsis Biological Resource Center (Ohio State University, Columbus, U.S.A.) and cotton seed from Rebecca Bennett (United States Department of Agriculture-Agricultural Research Service, Shafter, CA, U.S.A.); and purchased Bonny Best tomato seed from Millington Seed Co. (Vassar, MI, U.S.A.). Arabidopsis seed were sown on Jiffy 71 -in. by 1.25 -in. number 734 peat pellets while tomato and cotton seed were sown on 1.75 -in. by 1.75 -in. number 703 pellets (Growers Solution, Cookeville, TN, U.S.A.), and grown under cool white fluorescent lighting with moderate intensity during a 12 -h day length, with $30^{\circ} \mathrm{C}$ daytime and $27^{\circ} \mathrm{C}$ nighttime temperatures. $F$. oxysporum f. sp. conglutinans, $F$. oxysporum f. sp. raphani, and $F$. oxysporum $\mathrm{f}$. sp. mathioli originate from P. H. Williams through H. C. Kistler (Bosland and Williams 1987; Kistler et al. 1991); and F. oxysporum f. sp. vasinfectum race 4 strain WISC4 was obtained from R. Bennett. F. oxysporum f. sp. lycopersici race 3 strain MN-25 was obtained from H. C. Kistler (University of Minnesota, St. Paul, U.S.A.). F. oxysporum cultures were grown on Czapek-Dox minimal medium (Oxoid Ltd., Hampshire, U.K.), and conidial suspensions were harvested from 3to 5-day shaken cultures, washed three times, and resuspended in sterile water. To initiate a heavy infection, I adjusted $F$. $o x y$ sporum conidial suspensions to $10^{7}$ conidia $/ \mathrm{ml}$, using a hemacytometer, and irrigated peat pellets of 2 -week-old plants with F. oxysporum suspension or water (as a control).

\section{Staining of whole Arabidopsis root with $\mathrm{X}$ glycoside.}

A razor blade removed the shoot, and immersion of peat soil in tap water removed loose soil from roots. Roots were transferred to an aqueous solution of $0.1 \%$ Triton X-100 and 20 $\mathrm{mM}$ EDTA, pH8.0, and peat attached to roots was removed

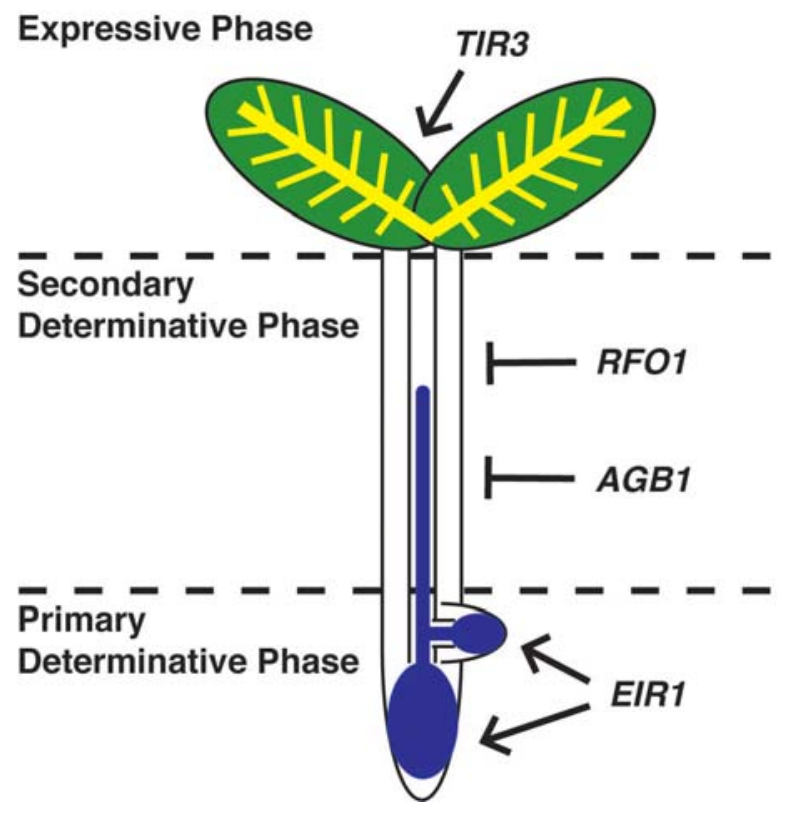

Fig. 7. Arabidopsis mutants affect specific phases of the infection cycle. Phenotypes of mutants agb1, eirl, rfol, and tir3 suggest roles for the wildtype genes in Fusarium wilt disease. In the primary determinative phase, EIRl facilitates penetration of root apices, both meristematic tips, and lateral root primordia, and initial colonization (dark color) of undifferentiated region of apices. In the secondary determinative phase, $A G B 1$ and RFOI confront Fusarium oxysporum's colonization (dark color) of vascular elements (an active response) or make the vascular elements incompatible with $F$. oxysporum colonization (a passive obstruction). In the expressive phase, TIR 3 promotes symptom development and necrosis in aboveground foliage. 
using fine, needle-sharp tweezers. The cleaned root system from one plant was spooled on wax paper, dried by drawing excess water with tissue paper, placed in an microfuge tube, and weighed.

Cleaned roots were incubated at $28^{\circ} \mathrm{C}$ in 40 -fold excess volume staining solution (e.g., $30 \mathrm{mg}$ of fresh weight in $1.2 \mathrm{ml}$ ) on a rotisserie tube mixer. Staining solution includes $10 \mathrm{mM}$ EDTA, $0.1 \%$ Triton $\mathrm{X}-100,1 \mathrm{mM} \mathrm{K}_{3} \mathrm{Fe}(\mathrm{CN})_{6}$, and $\mathrm{X}$ glycoside. Acidic or neutral $\mathrm{pH}$ staining buffer also contained $0.1 \mathrm{M}$ MES, $\mathrm{pH} 5.5$, or $0.1 \mathrm{M}$ sodium phosphate, $\mathrm{pH} 7.0$, respectively. Glycoside reagent stock solutions (100-fold, $2 \%$ ) were $20 \mathrm{mg}$ of X glycoside dissolved in $1 \mathrm{ml}$ of dimethylformamide (DMF). The following $X$ glycoside reagents (from Gold Biotechnologies, St Louis) were tested: X-Ara (catalog number B290), X-D-cellobioside (Chemical Abstracts Service [CAS] registry number 177966-52-8), X- $\alpha$-L-fucopyranoside (CAS 171869-92-4), X- $\beta$-D-fucopyranoside (CAS 17016-46-5) X-Nacetyl- $\beta$-D-galactosaminide (CAS $129572-48-1$ ), X- $\alpha$-D-galactopyranoside (CAS 107021-38-5), X- $\beta$-D-galactopyranoside (CAS 7240-90-6), X-GlcNAc (CAS 4264-82-8), X-Gluc, (CAS 114162-64-0), X- $\alpha$-D-xylopyranoside (catalog number B-530), and X- $\beta$-D-xylopyranoside (CAS 207606-55-1). Roots of Col-0 and Arabidopsis mutants were cleaned 7 days after soil was infested with $F$. oxysporum f. sp. conglutinans and then stained with $\mathrm{X}$-Ara overnight, left at $4^{\circ} \mathrm{C}$ for several hours to overnight, and transferred twice to excess water at $4^{\circ} \mathrm{C}$ for several hours to overnight. Blue precipitate staining was observed with a low-magnification dissecting microscope and recorded with a digital camera (Dino-Eye Eyepiece, AM423XC; BigC, Torrance, CA, U.S.A.). Magnified $(\times 20)$ digital images of all stained root apices of two root systems from each genotype were collected. Blind to genotype, image files were assigned to one of five categories, which are described in Results and Figure 5. Categorical results are presented as the fraction of root apices in a category among all stained root apices of a genotype.

$\mathrm{X}$-Ara and X-GlcNAc also stained pieces of $F$. oxysporum culture on minimal salt medium (MM) agar: in 1 liter, $3 \mathrm{~g}$ of $\mathrm{NaNO}_{3}, 1 \mathrm{~g}$ of $\mathrm{KH}_{2} \mathrm{PO}_{4}, 0.5 \mathrm{~g}$ of $\mathrm{MgSO}_{4}, 0.5 \mathrm{KCl}, 0.1 \mathrm{ml}$ of trace element solution, $1.6 \%$ agar, $2 \%$ carbon source, glucose, galactose, sucrose, xylose, or oat spelt xylan (number X4252; Sigma-Aldrich, St. Louis). Trace element solution (per $100 \mathrm{ml}$ ) consisted of $5 \mathrm{~g}$ of citric acid- $\mathrm{H}_{2} \mathrm{O}, 5 \mathrm{~g}$ of $\mathrm{ZnSO}_{4}-7 \mathrm{H}_{2} \mathrm{O}, 1 \mathrm{~g}$ of $\mathrm{Fe}\left(\mathrm{NH}_{4}\right)_{2}\left(\mathrm{SO}_{4}\right)_{2}-6 \mathrm{H}_{2} \mathrm{O}, 0.25 \mathrm{~g}$ of $\mathrm{CuSO}_{4}-5 \mathrm{H}_{2} \mathrm{O}, 0.05 \mathrm{~g}$ of $\mathrm{MnSO}_{4}-\mathrm{H}_{2} \mathrm{O}, 0.05 \mathrm{~g}$ of $\mathrm{MnSO}_{4}-\mathrm{H}_{2} \mathrm{O}, 0.05 \mathrm{~g}$ of $\mathrm{H}_{3} \mathrm{BO}_{3}$, and $0.05 \mathrm{~g}$ of $\mathrm{Na}_{2} \mathrm{MoO}_{4}-\mathrm{H}_{2} \mathrm{O}$.

\section{Quantifying $F$. oxysporum infection with NP-Ara.}

Root systems of the wild type, agbl, eirl, and $r f o l$ (in Fig. 4A and B) and the wild type and tir3 (Fig. 4C and D) were cleaned 8 and 9 days, respectively, after soil was infected with F. oxysporum f. sp. conglutinans. Roots were incubated for 20 $\mathrm{h}$ (unless specified otherwise) at $28^{\circ} \mathrm{C}$ on a rotisserie tube mixer in 40-fold volume staining solution, $0.1 \mathrm{M}$ sodium phosphate ( $\mathrm{pH} 7.0), 10 \mathrm{mM}$ EDTA, and $0.1 \%$ Triton $\mathrm{X}-100$ and NP-Ara (number N240; Gold Biotechnologies, St. Louis). NPAra $(100 \times, 4 \%)$ stock solution consists of $40 \mathrm{mg}$ of NP-Ara in $1 \mathrm{ml}$ of DMF. After incubation, sample solutions were frozen at $-20^{\circ} \mathrm{C}$ until the $\mathrm{OD}$ of all samples could be measured at 410 $\mathrm{nm}\left(\mathrm{OD}_{410 \mathrm{~nm}}\right)$ and $600 \mathrm{~nm}\left(\mathrm{OD}_{600 \mathrm{~nm}}\right)$ using a spectrophotometer (Smart Spec 3000; Bio-Rad, Philadelphia). OD $_{600 \mathrm{~nm}}$ was subtracted from $\mathrm{OD}_{410 \mathrm{~nm}}$ to account for nonspecific light diffraction in samples and give the $\mathrm{OD}_{410 \mathrm{~nm}}$ per gram of fresh weight of roots. The $\mathrm{OD}_{410 \mathrm{~nm}}$ per plant value was the number of grams fresh weight of a plant's whole root system multiplied by the same plant's $\mathrm{OD}_{410 \mathrm{~nm}}$ per gram of fresh weight. Measurements were standardized so that the mean $\mathrm{OD}_{410 \mathrm{~nm}}$ per gram of fresh weight and mean $\mathrm{OD}_{410 \mathrm{~nm}}$ per plant were 1 for uninfected wild type (in Fig. 4A and C) and infected wild type (in Fig. 4B and D), respectively.

To relate $\mathrm{ABF}$ activity to $F$. oxysporum biomass, a serial dilution of $F$. oxysporum f. sp. conglutinans in agar medium, $10^{7}$ and three 0.5 -fold serial dilutions of freshly harvested conidia was plated as a lawn, $35 \mathrm{~mm}$ in diameter, on MM agar supplemented with $1 \%$ oat spelt xylan to give between $10^{5}$ and $10^{6}$ conidia per square centimeter and were incubated for $20 \mathrm{~h}$ at $28^{\circ} \mathrm{C}$. A 1 -mm-diameter agar plug was incubated in a roughly 40-fold volume $(320 \mu \mathrm{l})$ of incubation buffer, $\mathrm{pH}$ 7.0, with $0.04 \% \mathrm{NP}$-Ara for $16 \mathrm{~h}$ at $28^{\circ} \mathrm{C}$ before measuring $\mathrm{OD}_{600 \mathrm{~nm}}$ and $\mathrm{OD}_{410 \mathrm{~nm}}$. $\mathrm{OD}_{600 \mathrm{~nm}}$ was subtracted from $\mathrm{OD}_{410 \mathrm{~nm}}$.

\section{ACKNOWLEDGMENTS}

I thank K. Hirschi, C. Kistler, and R. Bennett for critically reading the manuscript drafts, the Dean of Life Sciences, University of California, Los Angeles (UCLA) for funding, and UCLA undergraduate students $\mathrm{O}$. Alipour, K. Guiang, B. Pickett, A. Shu, and D. Tarashandegan for harvesting whole roots and documenting root apical staining patterns.

\section{LITERATURE CITED}

Anderson, J. P., Badruzsaufari, E., Schenk, P. M., Manners, J. M., Desmond O. J., Ehlert, C., Maclean, D. J., Ebert, P. R., and Kazan, K. 2004. Antagonistic interaction between abscisic acid and jasmonate-ethylene signaling pathways modulates defense gene expression and disease resistance in Arabidopsis. Plant Cell 16:3460-3479.

Bao, J. R., and Lazarovits, G. 2001. Differential colonization of tomato roots by nonpathogenic and pathogenic Fusarium oxysporum strains may influence Fusarium wilt control. Phytopathology 91:449-456.

Bao, J. R., Velemaa, J., Dobinson, K. F., and Lazarovitsa, G. 2000. Using GUS expression in a nonpathogenic Fusarium oxysporum strain to measure fungal biomass. Can. J. Plant Pathol. 24:340-348.

Beckman, C. H. 1987. The Nature of Wilt Diseases of Plants. American Phytopathological Society, St. Paul, MN, U.S.A.

Beckman, C. H., and Roberts, E. M. 1995. On the nature and genetic basis for resistance and tolerance to fungal wilt diseases of plants. Adv. Bot. Res. 21:35-77.

Berrocal-Lobo, M., and Molina, A. 2008. Arabidopsis defense response against Fusarium oxysporum. Trends Plant Sci. 13:145-150.

Boonsirichai, K., Sedbrook, J. C., Chen, R., Gilroy, S., and Masson, P. H. 2003. ALTERED RESPONSE TO GRAVITY is a peripheral membrane protein that modulates gravity-induced cytoplasmic alkalinization and lateral auxin transport in plant statocytes. Plant Cell 15:2612-2625.

Bosland, P. W., and Williams, P. H. 1987. An evaluation of Fusarium oxysporum from crucifers based on pathogenicity isozyme polymorphism, vegetative compatibility and geographic origin. Can. J. Bot. 65:2067-2073.

Chakravorty, D., Trusov, Y., and Botella, J. R. 2012. Site-directed mutagenesis of the Arabidopsis heterotrimeric $G$ protein $\beta$ subunit suggests divergent mechanisms of effector activation between plant and animal G proteins. Planta 235:615-627.

Couteaudier, Y., Daboussi, M. J., Eparvier, A., Langin, T., and Orcival, J. 1993. The GUS gene fusion system (Escherichia coli beta-D-glucuronidase gene), a useful tool in studies of root colonization by Fusarium oxysporum. Appl. Environ. Microbiol. 59:1767-1773.

Czymmek, K. J., Fogg, M., Powell, D. H., Sweigard, J., Park, S. Y., and Kang, S. 2007. In vivo time-lapse documentation using confocal and multi-photon microscopy reveals the mechanisms of invasion into the Arabidopsis root vascular system by Fusarium oxysporum. Fungal Genet. Biol. 44:1011-1023.

Diener, A. C., and Ausubel, F. M. 2005. RESISTANCE TO FUSARIUM OXYSPORUM 1, a dominant Arabidopsis disease-resistance gene, is not race specific. Genetics 171:305-321.

Dolan, L., Janmaat, K., Willemsen, V., Linstead, P., Poethig, S., Roberts, K., and Scheres, B. 1993. Cellular organisation of the Arabidopsis thaliana root. Development 119:71-84.

Eudes, A., Mouille, G., Thévenin, J., Goyallon, A., Minic, Z., and Jouanin, L. 2008. Purification, cloning and functional characterization of an endogenous beta-glucuronidase in Arabidopsis thaliana. Plant Cell Physiol. 49:1331-1341.

Gallagher, S. R., ed. 1992. GUS Protocols: Using the GUS gene as a reporter of gene expression. Academic Press, San Diego, CA, U.S.A.

Ishikawa, A. 2009. The Arabidopsis G-protein beta-subunit is required for 
defense response against Agrobacterium tumefaciens. Biosci. Biotechnol. Biochem. 73:47-52.

Ito, S., Nagata, A., Kai, T., Takahara, H., and Tanaka, S. 2005. Symptomless infection of tomato plants by tomatinase producing Fusarium oxysporum formae speciales nonpathogenic on tomato plants. Physiol. Mol. Plant Pathol. 66:183-191.

Jefferson, R. A., Kavanagh, T. A., and Bevan, M. W. 1987. GUS fusions: Beta-glucuronidase as a sensitive and versatile gene fusion marker in higher plants. EMBO (Eur. Mol. Biol. Organ.) J. 6:3901-3907.

Kanyuka, K., Praekelt, U., Franklin, K. A., Billingham, O. E., Hooley, R., Whitelam, G. C., and Halliday, K. J. 2003. Mutations in the huge Arabidopsis gene BIG affect a range of hormone and light responses. Plant J. 35:57-70.

Kazan, K., and Manners, J. M. 2009. Linking development to defense: Auxin in plant-pathogen interactions. Trends Plant Sci. 14:373-382.

Kidd, B. N., Kadoo, N. Y., Dombrecht, B., Tekeoglu, M., Gardiner, D. M., Thatcher, L. F., Aitken, E. A., Schenk, P. M., Manners, J. M., and Kazan, K. 2011. Auxin signaling and transport promote susceptibility to the root-infecting fungal pathogen Fusarium oxysporum in Arabidopsis. Mol. Plant-Microbe Interact. 24:733-748.

Kistler, H. C. 1997. Genetic diversity in the plant-pathogenic fungus Fusarium oxysporum. Phytopathology 87:474-479.

Kistler, H. C., Momol, E. A., and Benny, U. 1991. Repetitive genomic sequences for determining relatedness among strains of Fusarium oxysporum. Phytopathology 81:331-336.

Lagopodi, A. L., Ram, A. F., Lamers, G. E., Punt, P. J., Van den Hondel, C. A., Lugtenberg, B. J., and Bloemberg, G. V. 2002. Novel aspects of tomato root colonization and infection by Fusarium oxysporum f. sp. radicis-lycopersici revealed by confocal laser scanning microscopic analysis using the green fluorescent protein as a marker. Mol. PlantMicrobe Interact. 15:172-179.

Lawrence, G. J., Dodds, P. N., and Ellis, J. G. 2010. Transformation of the flax rust fungus, Melampsora lini: Selection via silencing of an avirulence gene. Plant J. 61:364-369.

Li, C., Chen, S., Zuo, C., Sun, Q, Ye, Q., and Yi, G. 2011. The use of GFPtransformed isolates to study infection of banana with Fusarium oxysporum f. sp. cubense race 4. Eur. J. Plant Pathol. 131:327-340.

Llorente, F., Alonso-Blanco, C., Sánchez-Rodriguez, C., Jorda, L., and Molina, A. 2005. ERECTA receptor-like kinase and heterotrimeric G protein from Arabidopsis are required for resistance to the necrotrophic fungus Plectosphaerella cucumerina. Plant J. 43:165-180.

Luschnig, C., Gaxiola, R. A., Grisafi, P., and Fink, G. R. 1998. EIR1, a root-specific protein involved in auxin transport, is required for gravitropism in Arabidopsis thaliana. Genes Dev. 12:2175-2187.

Ma, L. J., van der Does, H. C., Borkovich, K. A., Coleman, J. J., Daboussi, M. J., Di Pietro, A., Dufresne, M., Freitag, M., Grabherr, M., Henrissat, B., Houterman, P. M., Kang, S., Shim, W. B., Woloshuk, C., Xie, X., Xu, J. R., Antoniw, J., Baker, S. E., Bluhm, B. H., Breakspear, A., Brown, D. W., Butchko, R. A., Chapman, S., Coulson, R., Coutinho, P. M., Danchin, E. G., Diener, A., Gale, L. R., Gardiner, D. M., Goff, S., HammondKosack, K. E., Hilburn, K., Hua-Van, A., Jonkers, W., Kazan, K., Kodira, C. D., Koehrsen, M., Kumar, L., Lee, Y. H., Li, L., Manners, J. M., Miranda-Saavedra, D., Mukherjee, M., Park, G., Park, J., Park, S. Y., Proctor, R. H., Regev, A., Ruiz-Roldan, M. C., Sain, D., Sakthikumar, S., Sykes, S., Schwartz, D. C., Turgeon, B. G., Wapinski, I., Yoder, O., Young, S., Zeng, Q., Zhou, S., Galagan, J., Cuomo, C. A., Kistler, H. C., and Rep, M. 2010. Comparative genomics reveals mobile pathogenicity chromosomes in Fusarium. Nature 464:367-373.

Mace, M. E., Bell, A. A., and Beckman, C. H., eds. 1981. Fungal Wilt Diseases of Plants. Academic Press, New York

Maeda, K., Houjyou, Y., Komatsu, T., Hori, H., Kodaira, T., and Ishikawa, A. 2009. AGB1 and PMR5 contribute to PEN2-mediated preinvasion resistance to Magnaporthe oryzae in Arabidopsis thaliana. Mol. PlantMicrobe Interact. 22:1331-1340.

Michielse, C. B., and Rep, M. 2009. Pathogen profile update: Fusarium oxysporum. Mol. Plant Pathol. 10:311-324.

Mudgil, Y., Uhrig, J. F., Zhou, J., Temple, B., Jiang, K., and Jones, A. M. 2009. Arabidopsis N-MYC DOWNREGULATED-LIKE1, a positive regulator of auxin transport in a $\mathrm{G}$ protein-mediated pathway. Plant Cell 21:3591-3609.

Mullins, E. D., and Kang, S. 2001. Transformation: A tool for studying fungal pathogens of plants. Cell. Mol. Life Sci. 58:2043-2052.

Olivain, C., Humbert, C., Nahalkova, J., Fatehi, J., L'Haridon, F., and Alabouvette, C. 2006. Colonization of tomato root by pathogenic and nonpathogenic Fusarium oxysporum strains inoculated together and separately into the soil. Appl. Environ. Microbiol. 72:1523-1531.

Ospina-Giraldo, M. D., Mullins, E., and Kang, S. 2003. Loss of function of the Fusarium oxysporum SNF1 gene reduces virulence on cabbage and Arabidopsis. Curr. Genet. 44:49-57.

Panagiotou, G., Topakas, E., Economou, L., Kekos, D., Macris, B. J., and Christakopoulos, P. 2003. Induction, purification, and characterization of two extracellular alpha-L-arabinofuranosidases from Fusarium oxysporum. Can. J. Microbiol. 49:639-644.

Papadopoulou, K. K., Kavroulakis, N., Tourn, M., and Aggelou, I. 2005. Use of $\beta$-glucuronidase activity to quantify the growth of Fusarium oxysporum f. sp. radicis-lycopersici during infection of tomato. J. Phytopathol. 153:325-332.

Park, J. H., Halitschke, R., Kim, H. B., Baldwin, I. T., Feldmann, K. A., and Feyereisen, R. 2002. A knock-out mutation in allene oxide synthase results in male sterility and defective wound signal transduction in Arabidopsis due to a block in jasmonic acid biosynthesis. Plant J. 31:112.

Roberts, I. N., Oliver R. P., Punt, P. J., and van den Hondel, C. A. 1989. Expression of the Escherichia coli beta-glucuronidase gene in industrial and phytopathogenic filamentous fungi. Curr. Genet. 15:177-180.

Ruegger, M., Dewey, E., Hobbie, L., Brown, D., Bernasconi, P., Turner, J., Muday, G., and Estelle, M. 1997. Reduced naphthylphthalamic acid binding in the tir3 mutant of Arabidopsis is associated with a reduction in polar auxin transport and diverse morphological defects. Plant Cell 9:745-757.

Sarrocco, S., Falaschi, N., Vergara, M., Nicoletti, F., and Vannacci, G. 2007 Use of Fusarium oxysporum f. sp. dianthi transformed with marker genes to follow colonization of carnation roots. J. Plant Pathol. 89:47-54.

Sieberer, T., Seifert, G. J., Hauser, M. T., Grisafi, P., Fink, G. R., and Luschnig, C. 2000. Post-transcriptional control of the Arabidopsis auxin efflux carrier EIR1 requires AXR1. Curr. Biol. 10:1595-1598.

Smith, R., and Walker, J. C. 1930. A cytological study of cabbage plants in strains susceptible or resistant to yellows. J. Agric. Res. 41:17-35.

Talboys, P. W. 1972. Resistance to vascular wilt fungi. Proc. R. Soc. Lond. Ser. B Biol. Sci. 181:319-332.

Temple, B. R., and Jones, A. M. 2007. The plant heterotrimeric G-protein complex. Annu. Rev. Plant Biol. 58:249-266.

Thatcher, L. F., Manners, J. M., and Kazan, K. 2009. Fusarium oxysporum hijacks COI1-mediated jasmonate signaling to promote disease development in Arabidopsis. Plant J. 58:927-939.

Trusov, Y., Rookes, J. E., Chakravorty, D., Armour, D., Schenk, P. M., and Botella, J. R. 2006. Heterotrimeric G proteins facilitate Arabidopsis resistance to necrotrophic pathogens and are involved in jasmonate signaling. Plant Physiol. 140:210-220.

Trusov, Y., Sewelam, N., Rookes, J. E., Kunkel, M., Nowak, E., Schenk, P. M., and Botella, J. R. 2009. Heterotrimeric G proteins-mediated resistance to necrotrophic pathogens includes mechanisms independent of salicylic acid-, jasmonic acid/ethylene- and abscisic acid-mediated defense signaling. Plant J. 58:69-81.

Turlier, M. F., Eparvier, A., and Alabouvette, C. 1994. Early dynamic interactions between Fusarium oxysporum f. sp. lini and the roots of Linum usitatissimum as revealed by transgenic GUS-marked hyphae. Can. J. Bot. 72:1605-1612.

van der Does, H. C., Duyvesteijn, R. G., Goltstein, P. M., van Schie, C. C., Manders, E. M., Cornelissen, B. J., and Rep, M. 2008. Expression of effector gene SIX1 of Fusarium oxysporum requires living plant cells. Fungal Genet. Biol. 45:1257-1264.

Vierheilig, H., Schweiger, P., and Brundrett, M. 2005. An overview of methods for the detection and observation of arbuscular mycorrhizal fungi in roots. Physiol. Plant. 125:393-404. 